\title{
In vitro evaluation of the schistosomicidal effect of the extracts, fractions and major 3-hydroxy-2,6-dialkyl-substituted piperidine alkaloids from the flowers of Senna spectabilis (Fabaceae)
}

\author{
Andreísa Teixeira de Castro ${ }^{a}$, Aline Pereira Castro ${ }^{a}$, Matheus Siqueira Silva ${ }^{a}$, \\ Isabella Maria Monteiro de Souza ${ }^{a}$, Raquel Lopes Martins-Souza ${ }^{a}$, Daniela Aparecida Chagas-Paula ${ }^{a}$, \\ Luiz Felipe Leomil Coelho ${ }^{a}$, Vanderlan da Silva Bolzani ${ }^{b}$, Marcos Pivatto ${ }^{c}$, Claudio Viegas Junior ${ }^{\mathrm{a}}$, \\ Marcos José Marques ${ }^{a, *}$ \\ a Universidade Federal de Alfenas Minas Gerais, Alfenas 37130-000, Brazil \\ ${ }^{\mathrm{b}}$ Universidade Estadual Paulista São Paulo, Araraquara 14800-060, Brazil \\ ' Universidade Federal de Uberlândia Minas Gerais, Uberlândia 38408-100, Brazil
}

\section{A R T I C L E I N F O}

\section{Article history:}

Received 1 June 2016

Revised 22 July 2016

Accepted 23 July 2016

Available online 25 July 2016

\section{Keywords:}

Schistosomiasis

Senna spectabilis

Alkaloids

Fluorescent probes

\begin{abstract}
A B S T R A C T
In this work, we present the in vitro schistosomicidal activity evaluation of the most active dichloromethane fraction $(\mathrm{FDm})\left(\mathrm{ED}_{50}=83.5 \mu \mathrm{g} / \mathrm{mL}\right)$ and of a mixture of the major alkaloids $((-)$-cassine $/(-)$-spectaline, $C / E)\left(E_{50}=37.4 \mu \mathrm{g} / \mathrm{mL}\right)$ from the flowers of Senna spectabilis against adult worms and cercariae. We also demonstrate other toxic effects including paralysis of the adult worms, inhibition of the secretory activity, tegument lesions and cercaricidal activity. In the association test of Praziquantel (PZQ)-C/E, we observed up to $80 \%$ mortality of Schistosoma mansoni in comparison to PZQ monotherapy. Due to the diversity of the toxic effects, the schistosomicidal activity of $\mathrm{C} / \mathrm{E}$ is likely a result of a multitarget mechanism involving the tegument, secretory system and neuromotor action.
\end{abstract}

(c) 2016 Elsevier Ltd. All rights reserved.
Schistosomiasis is a chronic parasitic disease caused by parasites of the genus Schistosoma. It is included in the list of neglected diseases by the World Health Organization (WHO) and presents significant social and economic impacts. ${ }^{1-3}$ It is estimated that more than 207 million people are infected, and approximately 250 thousand die each year worldwide by consequences of the infection of Schistosoma. ${ }^{1-4}$

Currently, chemotherapy is the first-line tool to minimize the prevalence and incidence of this disease worldwide, ${ }^{5}$ but the only drug available and indicated by WHO for treatment is praziquantel (PZQ). However, the dependence on a single drug is worrying, especially in endemic areas where retreatment is constant and may favor the emergence of drug-resistant strains. Due to the warnings about drug resistance, possible infection recurrence, low efficacy in some cases and very restricted therapeutic alternatives, the search for new drug prototypes is a continuous challenge and must be encouraged in academia and the pharmaceutical industry. ${ }^{6,7}$ In the past few years, the interest in natural products as a potential source for the treatment of parasitic diseases has

\footnotetext{
* Corresponding author.

E-mail address: marques@unifal-mg.edu.br (M.J. Marques).
}

grown. $^{8}$ The objective of these studies is to propose alternative methods for the treatment of these diseases, especially for neglected ones, such as schistosomiasis, ${ }^{9}$ since this has left researchers on alert regarding the development of resistance to the only drug used for its treatment. As part of the great effort in prospective studies on new drug candidates for all neglected diseases, several recent in vitro studies have been performed in the search for new schistosomicidal compounds from plants. ${ }^{9-12}$

Plants produce a great diversity of secondary metabolites with a very wide spectrum of biological activity, including cytotoxic, antiparasitic and antimicrobial properties. These compounds frequently interfere with central targets in the parasites, such as DNA (e.g., intercalation, alkylation activity), membrane integrity, microtubules and neuronal signal transduction. ${ }^{13}$ The Senna genus comprises about 600 species distributed worldwide; some species have evoked interest due to the abundance of 2,6-dialkyl-3-Osubstituted piperidine alkaloids in leaves, flowers and fruits. Biological studies with extracts from Senna species (specially S. carnaval, S. excelsa and S. spectabilis) have shown a number of relevant effects, such as antimicrobial, sedative, anticonvulsant, antioxidant, antinociceptive, anti-inflammatory and leishmanicidal effects. ${ }^{14-20}$ In Brazil, Senna spectabilis, S. carnaval and 
S. excelsa are endemic species of southeast states and have been identified as important sources of piperidine alkaloids, which have demonstrated sedative, anticonvulsant, ${ }^{14}$ antimicrobial, antioxidant, $^{21}$ anti-inflammatory ${ }^{22}$ and central nervous system effects, ${ }^{20,23}$ including the inhibition of acetylcholinesterase and central analgesia. Recently, antiparasitic activity was also reported against Leishmania major promastigotes of the crude extract, fractions and a mixture of the two major alkaloids (-)-cassine/(-)-spectaline (C/E) from flowers of S. spectabilis. ${ }^{15}$

Due to our interest in the search for new bioactive compounds against schistosomiasis and other neglected parasitic diseases, and considering earlier reports about the promising antiparasitic activity of S. spectabilis, we decided to investigate the in vitro schistosomicidal activity of the crude extract, its fractions and a mixture of the two major alkaloidal constituents (Fig. 1).

Flowers of $S$. spectabilis were collected in the region of Araraquara-SP (Brazil) during January 2013. A voucher specimen was deposited in the Herbarium of the Botanical Garden of São Paulo under registry number SP 370.917. Extraction procedures and the isolation of (-)-cassine and (-)-spectaline substances were performed as described by Albuquerque Melo and co-workers. ${ }^{15}$ The alkaloidal portion was then purified by column chromatography ( $\mathrm{CC}$, neutral $\mathrm{Al}_{2} \mathrm{O}_{3}$ ) and eluted with EtOH$/ \mathrm{CHCl}_{3}$ / hexanes (1:7:2), providing a mixture of piperidine alkaloids $(-)$-cassine/(-)-spectaline (4.82 $\mathrm{g}$ ) along with a complex mixture of other more polar alkaloidal metabolites. It is known that almost all alkaloids from $S$. spectabilis flowers occur in mixtures of two homologue-derivatives, differing only by two methylene units in the side chain. ${ }^{24}$ Therefore, the mixtures of such homologues is very difficult to separate, and it was decided to evaluate the mixture of the most abundant alkaloids, (-)-cassine/(-)-spectaline. The $\mathrm{C} / \mathrm{E}$ proportion in the mixture was determined by liquid chromatography coupled with mass spectrometry. The mass spectrum of the C/E mixture (Fig. 2) revealed that these two alkaloids are practically pure in the mixture, through identification of the respective molecular ions $[\mathrm{M}+\mathrm{H}]^{+}$with 298.2 and $326.3 \mathrm{~m} / \mathrm{z}$, respectively, with (-)-cassine as the major constituent in the mixture at a proportion of $57 \%$ in relation to (-)-spectaline (Table 1 ).

The occurrence of mixtures of several homologous alkaloids, such as (-)-cassine and (-)-spectaline, with very similar chromatographic behavior in $S$. spectabilis had already been reported. ${ }^{24}$ In this study, the authors have identified and characterized several of these metabolites, including their typical fragmentation data by mass spectrometry. ${ }^{20,24}$ Therefore, this study was limited to a comparison of the chromatographic data obtained during the isolation and purification stage, using the mass spectrometry only for relative quantification among the most abundant alkaloids, (-)-cassine and (-)-spectaline.

To evaluate schistosomicidal activity, the parasites were recovered from experimental animals infected by the S. mansoni LE (Luiz Evangelista) strain. This strain has been routinely maintained by serial passages in Biomphalaria glabrata models and mice of Swiss

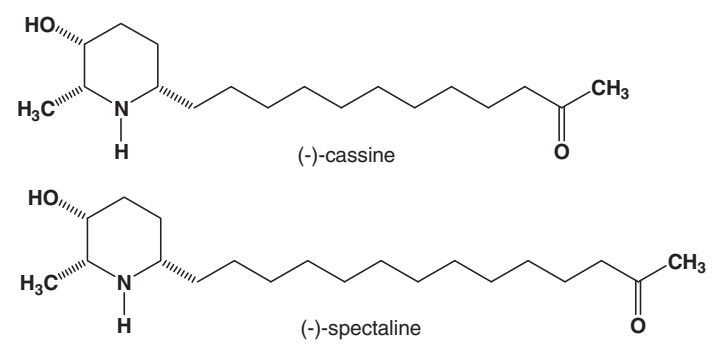

Figure 1. Chemical structures of (-)-cassine and (-)-spectaline, the two major alkaloids from flowers of S. spectabilis.

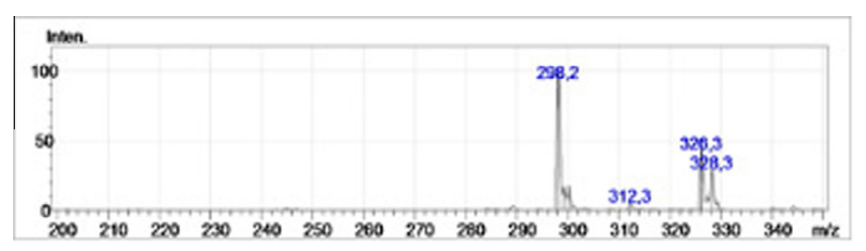

Figure 2. Mass spectrum of the mixture of (-)-cassine and (-)-spectaline isolated from $S$. spectabilis flowers.

Table 1

Relative abundance of (-)- cassine and (-)-spectaline in the evaluated mixture

\begin{tabular}{|c|c|c|}
\hline Substance & (-)-Cassine & (-)-Spectaline \\
\hline$m / z$ & 298.20 & 326.25 \\
\hline $\begin{array}{l}\text { Absolute } \\
\text { intensity }\end{array}$ & $15,206,026$ & $6,596,588$ \\
\hline $\begin{array}{l}\text { Relative } \\
\quad \text { intensity }\end{array}$ & 100.00 & 43.38 \\
\hline Main fragment & {$[\mathrm{M}+\mathrm{H}]^{+}$} & {$[\mathrm{M}+\mathrm{H}]^{+}$} \\
\hline Fragmentation & $279.6,108.8$ & $308.2,141.0$ \\
\hline $\begin{array}{l}\text { Fragmentation } \\
\text { pattern }^{24}\end{array}$ & $\begin{array}{l}280\left[\mathrm{M}-\mathrm{H}_{2} \mathrm{O}\right]^{+} \text {(relative } \\
\text { intensity } 100 \text { ), } 109 \text { not } \\
\text { assigned (relative intensity } 10 \text { ) }\end{array}$ & $\begin{array}{l}308\left[\mathrm{M}-\mathrm{H}_{2} \mathrm{O}\right]^{+} \\
\text {(relative intensity } 10 \text { ), } \\
141 \text { not assigned } \\
\text { (relative intensity 8) }\end{array}$ \\
\hline
\end{tabular}

lineage for more than 30 years at the Research Center René Rachou/Oswaldo Cruz Foundation. The Ethics Committee on Animals at the Federal University of Alfenas (UNIFAL-MG) authorized all procedures, under registration number 544/2013 (on January 20th, 2014) in accordance with the ethical principles required for animal experimentation.

Mice infected with $S$. mansoni cercariae (LE strain) were sacrificed 45 days after infection by 'overdose' with $10.0 \%$ ketamine chloride (Ketamine Agener) and 2.0\% xylazine hydrochloride (Rompun) dissolved in saline, which was administered intraperitoneally ( $\pm 0.2 \mathrm{~mL}$ per animal). Subsequently, retrograde liver perfusion was performed according to the method of Smithers and Terry $^{25}$ to obtain the parasites. Subsequently, the in vitro activity of the ethanolic extract, its fractions, and the mixture of C/E against S. mansoni adult worms was evaluated using a methodology adapted from the literature. $^{26}$

The recovered parasites were cultivated in six-well culture plates (four couples per well) in RPMI-1640 culture medium supplemented with heat-inactivated $5.0 \%$ fetal bovine serum with $1.0 \%$ penicillin $(10,000 \mathrm{IU} / \mathrm{mL})$ and streptomycin $(10.0 \mathrm{mg} / \mathrm{mL})$ (Sigma, USA). After thirty minutes of adaptation, the ethanolic extract (EEt), ethyl acetate fraction (FAE), dichloromethane fraction (FDm) and C/E samples were added to the cultures at different concentrations (EEt and FAE at 50.0; 75.0; 100.0; and $150.0 \mu \mathrm{g} / \mathrm{mL}$; FDm and C/E at 30.0, 40.0, 50.0, 75.0, 100.0 and $150.0 \mu \mathrm{g} / \mathrm{mL}$ ). The plates were incubated at $37{ }^{\circ} \mathrm{C}$ and $5.0 \% \mathrm{CO}_{2}$ and then analyzed within 2 and $24 \mathrm{~h}$ after contact with the substance samples. The test groups were compared with the controls of supplemented RPMI 1640 medium, methanol (used as solvent for the samples) and PZQ $(2 \mu \mathrm{g} / \mathrm{mL})$ under the same conditions described above.

The parasites in culture exposed to different samples were evaluated for effects on movement, mating, contraction, morphological tegument alterations and egg laying over the course of eight days. These parameters have also been used in previous studies as indicators of biological activity and toxicity studies with Schistosoma species. ${ }^{1,12,27-29}$ After eight days of contact between the extracts/ compounds and the parasites, the effective dose $\left(E D_{50}, E_{90}\right.$ and $\mathrm{ED}_{100}$ ) were determined from sigmoidal regression curves. The $\mathrm{ED}_{50,90,100}$ values were the concentration of $\mathrm{C} / \mathrm{E}$ required bringing about $50.0,90.0$ and $100.0 \%$ death of adult worms of S. mansoni. These values were calculated from survival curves by sigmoidal 

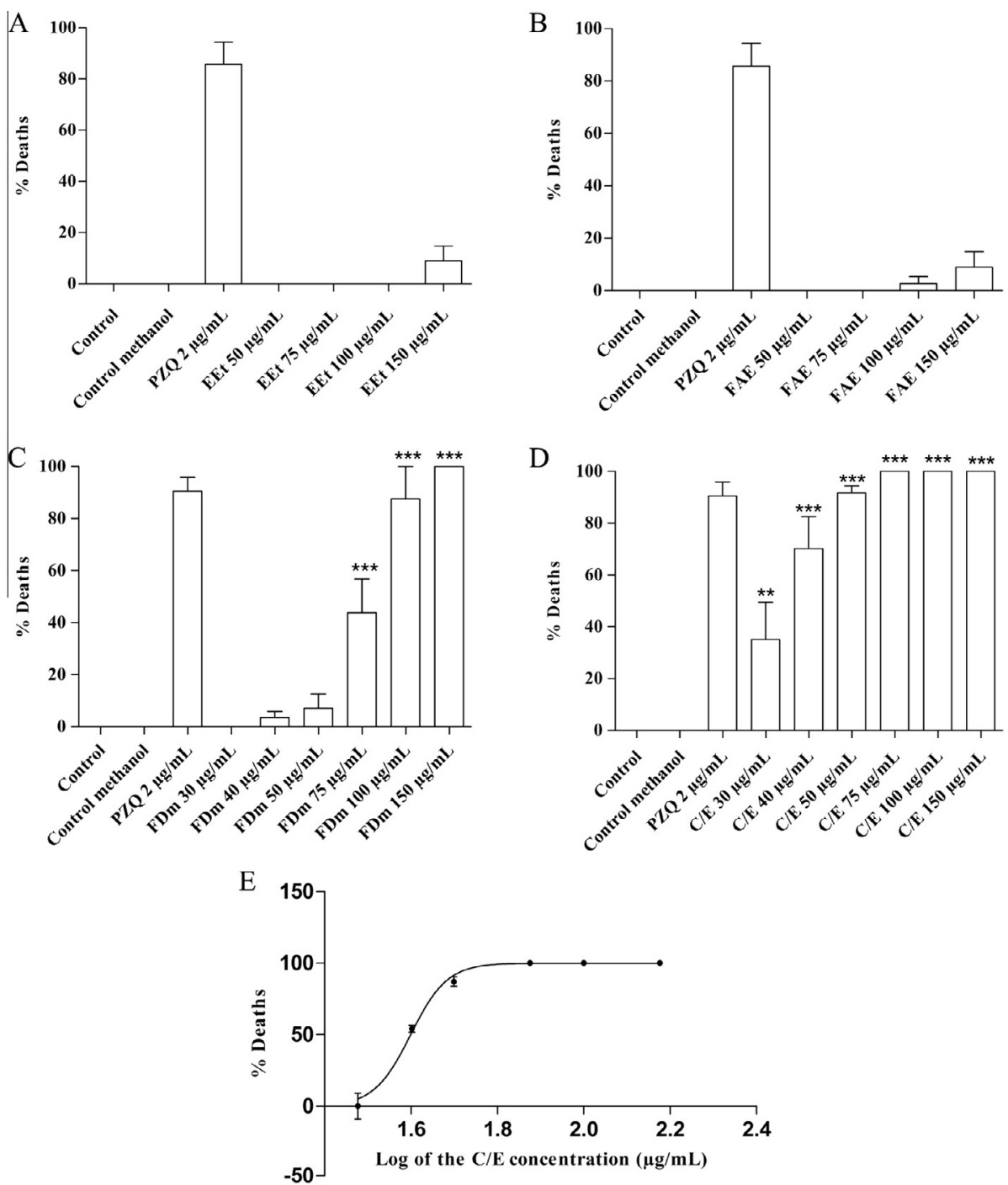

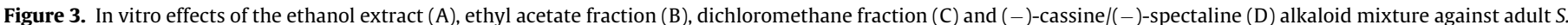

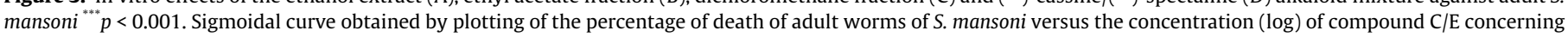
the calculation of $\mathrm{ED}_{50,90,100}(\mathrm{E})$.

model. They took into account the percent of death of adult worms versus $\log \mathrm{C} / \mathrm{E}$ concentration, besides of the non-linear regression analyses by Graph Pad Prism 5.0 software (Graph Pad Software Inc., San Diego, CA, USA). The effective dose values were used to assess the potency of activity of compounds and to monitor the resistance and susceptibility profiles of the parasite strain in relation to the evaluated substance. $8,28,30,31$

Adult worms exposed to concentrations of 50.0, 75.0 and $100.0 \mu \mathrm{g} / \mathrm{mL}$ of the EEt maintained normal movement and mating, with no evidence of tegument injury. In addition, egg laying was observed over eight days of experiment. However, the morphology of the parasites seemed to be altered, with elongated worms and some with stationary digestive systems, in addition to smaller quantities of egg laying compared to the control.

On the eighth day of the experiment, many eggs were unviable, and some parasites were immobile. The FAE fraction at the concentration of $50.0 \mu \mathrm{g} / \mathrm{mL}$, after $24 \mathrm{~h}$, did not alter parasite mating, although movement was decreased. At higher concentrations ( 100.0 and $150.0 \mu \mathrm{g} / \mathrm{mL}$ ), there was tegument injury as well as paralysis of some parasites. The high inhibitory concentration for $50 \%$ $\left(\mathrm{ED}_{50}\right)$ for EEt $(495.4 \mu \mathrm{g} / \mathrm{mL}$, Fig. 3A) and FAE $(553.5 \mu \mathrm{g} / \mathrm{mL}$, Fig. 3B) shows that the viability of the worms was not significantly different when compared to the controls RPMI 1640 medium and methanol.
In contrast, adult worms exposed to FDm for two hours, at all concentrations, showed flaccid paralysis. However, at lower concentrations (30.0; 40.0; and $50.0 \mu \mathrm{g} / \mathrm{mL}$ ), after washing to remove the active compound, worms recovered even a small amount of egg laying. At concentrations of $75.0,100.0$ and $150.0 \mu \mathrm{g} / \mathrm{mL}$, all parasites remained elongated until the eighth day and displayed tegument lesions. The $\mathrm{ED}_{50}, \mathrm{ED}_{90}$ and $\mathrm{ED}_{100}$ values for $\mathrm{FDm}$ were $83.5 \mu \mathrm{g} / \mathrm{mL}, 122.3 \mu \mathrm{g} / \mathrm{mL}$ and $132.0 \mu \mathrm{g} / \mathrm{mL}$, respectively (Fig. $3 \mathrm{C}$ ), which clearly show a promising anti-parasitic effect, with results statistically significant $(p<0.05)$ compared to the control (methanol) at concentrations of $75.0,100.0$ and $150.0 \mu \mathrm{g} / \mathrm{mL}$.

A comparison of the effects on parasites exposed to EEt, FAE and FDm clearly show that FDm caused greater damage to the worms than the other compounds tested. This effect could be explained by the results from a previous work, ${ }^{15}$ in which the authors identified (-)-cassine and (-)-spectaline as the major constituents of the dichloromethane fraction of the crude ethanolic extract of flowers from $S$. spectabilis.

After two hours of administration of $150.0 \mu \mathrm{g} / \mathrm{mL}$ of C/E, parasites became stationary and elongated (Fig. 4). After $24 \mathrm{~h}, \mathrm{C} / \mathrm{E}$ was removed from the culture by washing and it was observed that the parasites exposed to lower concentrations (30.0 and $40.0 \mu \mathrm{g}$ / $\mathrm{mL}$ ) restored a little mobility. In contrast, those parasites exposed 


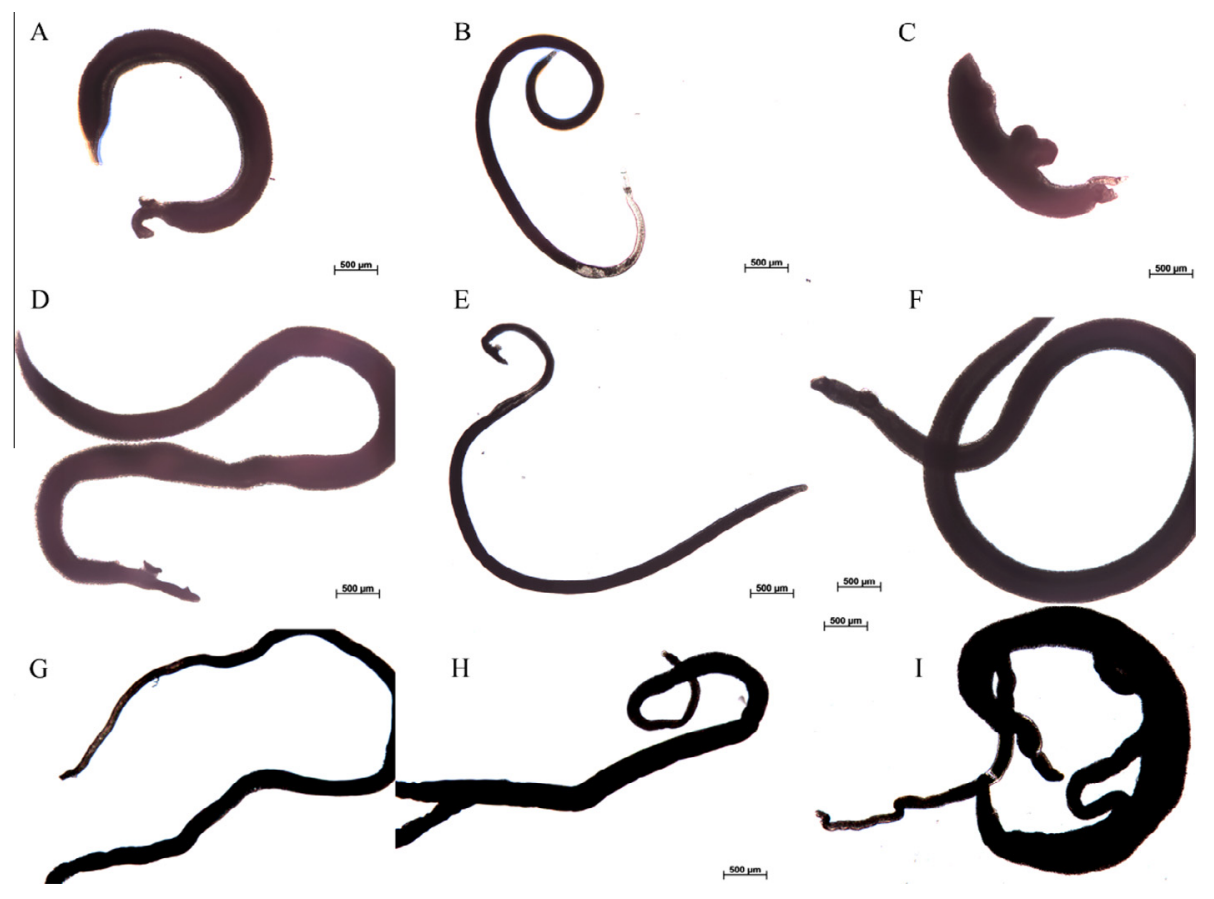

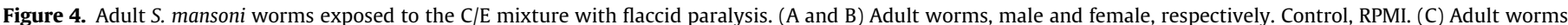

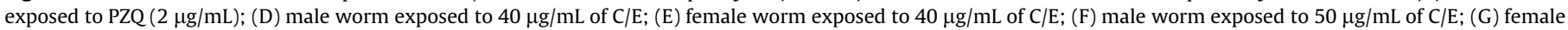
worm exposed to $75 \mu \mathrm{g} / \mathrm{mL}$ of $\mathrm{C} / \mathrm{E}$; (H) female worm exposed to $100 \mu \mathrm{g} / \mathrm{mL}$ of C/E; (I) mated worms exposed to $150 \mu \mathrm{g} / \mathrm{mL}$ of $\mathrm{C} / \mathrm{E}$. (Scale bar $=500 \mu \mathrm{m}$.)

to higher concentrations remained without movement, with $\mathrm{ED}_{50}$, $\mathrm{ED}_{90}$ and $\mathrm{ED}_{100}$ values of $34.7,82.8$ and $94.8 \mu \mathrm{g} / \mathrm{mL}$, respectively (Fig. 3E). In all concentrations there was significant statistical difference $(p<0.05)$ when compared with the control, as shown in the graph below (Fig. 3D). Additionally, it was observed that in all concentrations there were parasites with tegument lesions.

In fact, we observed a stronger effect on worm musculature for FDm and C/E than for EEt and FAE. Furthermore, flaccid paralysis as well as tegument damage was observed in parasites of both sexes, with a stronger effect on females. These effects occurred most strongly within $24 \mathrm{~h}$ of contact with the active substances, causing a flaccid paralysis identified by worm elongation (Fig. 4).

Our results were corroborated by previous studies that had reported the neurotoxic properties of these types of alkaloids, probably acting as agonists or antagonists of neuroreceptors or ion channels. ${ }^{13}$ Multicellular parasites have a nervous system that utilizes neurotransmitters such as acetylcholine (ACh) and AChreceptors, which are responsible for controlling worm muscle activity. ${ }^{13}$ Therefore, inhibition of the activity of these neuroreceptors may result in muscle paralysis, as was observed for PZQ but involving a different mechanism. It is believed that PZQ blocks sodium and potassium channels responsible for neuronal signaling and also causes the direct paralysis and death of worms. ${ }^{32,33}$

It was reported that acetylcholinesterase enzyme (AChE) is found in cercariae and schistosomules ${ }^{34}$ and is present in two forms in parasites. One is internally associated with muscle mass and has a functional role in the motor plates of parasites. The other form is external, associated with the tegument, and involved in signal transduction. ${ }^{35}$ Therefore, the function of $\mathrm{ACh}$ as a neurotransmitter is reinforced by the fact that the worm possesses enzymes for its synthesis and degradation. Additional evidence for the physiological role of ACh in S. mansoni is that muscular activity of this worm is reduced by cholinomimetic agents such as carbachol, nicotine and AChE inhibitors that produce flaccid paralysis, which can be defined as a loss of motility accompanied by worm elongation due to relaxation of its longitudinal musculature. $^{36,37}$ In an in vivo study with a series of piperidine alkaloid derivatives, it was found that these compounds could act as AChE inhibitors, with selectivity for cerebral AChE. ${ }^{38}$ Thus, considering that 3-hydroxy-2,6-dialkyl-susbtituted piperidine derivatives could act as AChE inhibitors, with possible action on ACh receptors, our results may be explained by the action of $\mathrm{C} / \mathrm{E}$ in direct muscle paralysis and parasite death.

In vitro evaluation of the excretory system activity in adult worms was also performed by using resorufin incubated with $\mathrm{C} / \mathrm{E}$, as described by Castro and co-workers. ${ }^{26}$ Figure $5 \mathrm{~A}-\mathrm{C}$ shows normal functioning of the excretory system of adult $S$. mansoni worms from the RPMI and methanol control groups after labeling with the resorufin probe. In this case, fluorescence was clearly delimited along the parasite when expelling the probe from the organism. The parasites exposed to $2 \mu \mathrm{g} / \mathrm{mL}$ of PZQ (Fig. 5D) and $40 \mu \mathrm{g} / \mathrm{mL}$ of $\mathrm{C} / \mathrm{E}$ (Fig. 5E and F) displayed excretory system damage, showing a pattern of differential fluorescence, which emissions scattered throughout the body. According to Sato et al., ${ }^{39}$ the resorufin probe is a salt of fluorescent nature besides a substrate P-glycoprotein (Pgp) modulator, a protein expressed in the excretory epithelium of $S$. mansoni adult worms. These proteins are associated with the absorption, elimination and distribution of many drugs. ${ }^{40}$

The in vitro assessment of tegument damage in adult worms exposed to a mixture of C/E was evaluated by the Hoechst 33258 probe, using a procedure adapted from Castro and co-workers. ${ }^{26}$ The tegument of $S$. mansoni adult worms has been the subject of investigation as a promising target for schistosomicidal agents, since it is responsible for one of the parasite escape mechanisms from the immune system in the human body. ${ }^{41,42}$ Hoechst 33258 is a hydrophilic probe that emits fluorescence when it binds to the cell DNA. So, in the presence of lesions, this probe diffuses itself, acting as an indicator of membrane integrity. ${ }^{43}$ In Figure $6 \mathrm{E}$ and $\mathrm{F}$, fluorescence is seen emitted from the parasite after exposure to $\mathrm{C} / \mathrm{E}$, which is compatible with observations of the worm under the action of PZQ (Fig. 6D). These effects were not observed in the RPMI medium and methanol group controls (6A, 6B and 6C). Once again, the tegument lesions were more significant in females, 

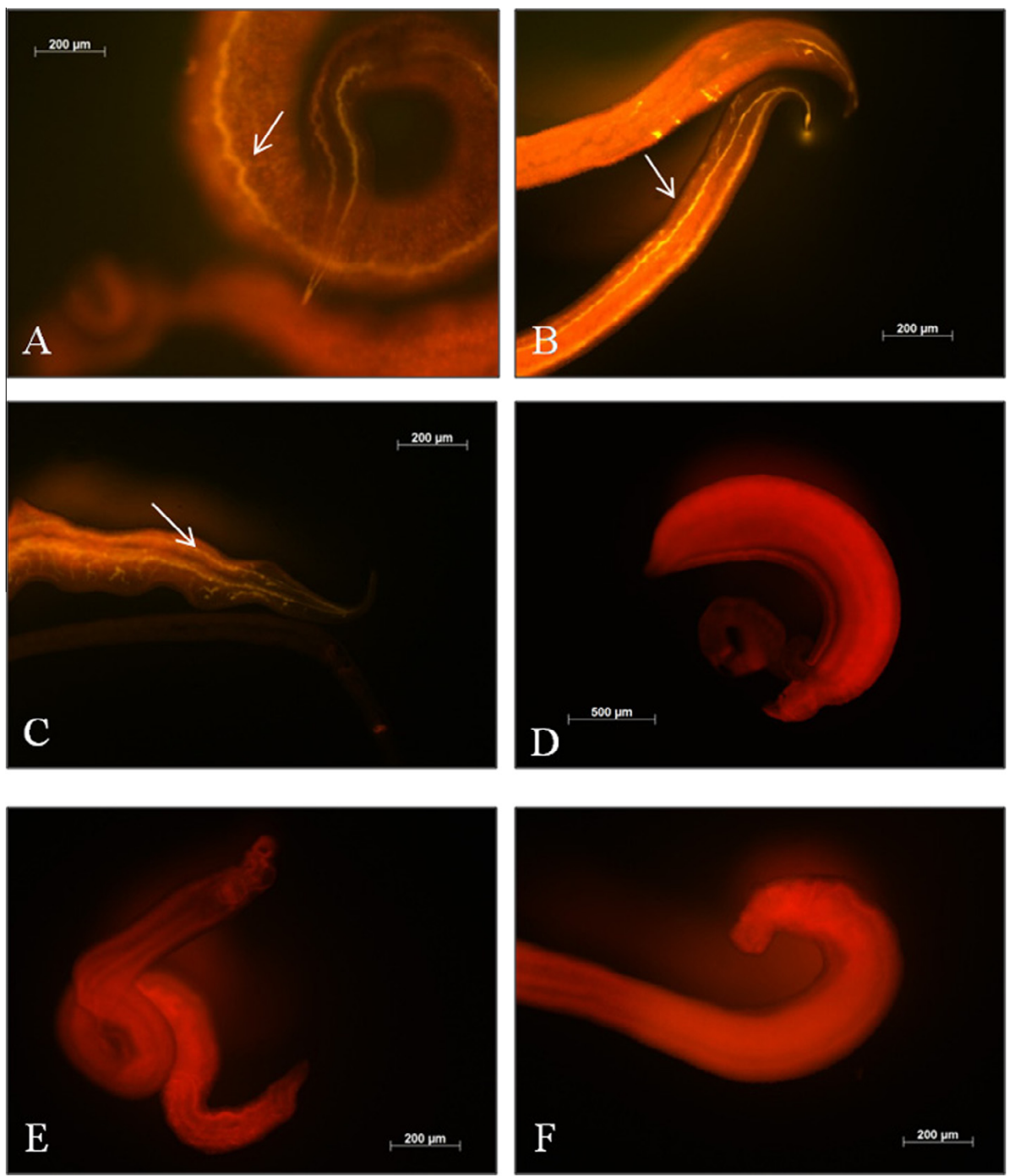

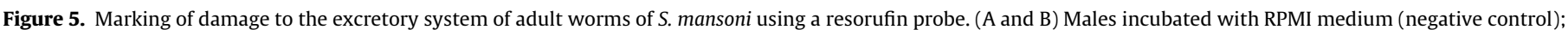
(C) males exposed to methanol; (D) coupled worms exposed to $2.0 \mu \mathrm{g} / \mathrm{mL} \mathrm{PZQ}$ (positive control); (E and F) males exposed to the C/E mixture at $40.0 \mu \mathrm{g} / \mathrm{mL}$.

causing blistering in greater quantity and a greater proportion of the cutaneous surface to be stained by the probe (Fig. 6E and F). Therefore, these results make it clear that the C/E mixture is responsible for damage to the tegument of adult worms, because it is able to inflict damage on the $S$. mansoni excretory system.

We also evaluated the in vitro effect of an association of $C / E$ and PZQ on S. mansoni adult worms, because chemotherapy with a combination of different drugs has been used for the treatment of infectious disease in order to delay or prevent an increase in drug resistance. ${ }^{43-45}$ The methodology was modified from that proposed by Araujo and co-workers. ${ }^{44}$ After thirty minutes of adaptation of the parasites, a solution of $\mathrm{C} / \mathrm{E}$ in methanol $(5.0 \mathrm{mg} / \mathrm{mL})$ and PZQ solubilized in RPMI-1640 $(0.8 \mathrm{mg} / \mathrm{mL})$ was added to the cultures. For this purpose, we used associations of PZQ:C/E in the following proportions $(\mu \mathrm{g} / \mathrm{mL}): 0.5: 23.8,0.5: 11.9$, $0.5: 6.0 ; 0.25: 23.8,0.25: 11.9,0.25: 6.0$. Ten wells were used as controls, of which four contained PZQ $(2.0,0.5,0.25$ and $0.125 \mu \mathrm{g} / \mathrm{mL})$, four contained C/E $(47.5,23.8,11.9$ and $6.0 \mu \mathrm{g} / \mathrm{mL})$, one well contained only supplemented culture medium and another with methanol (1\%) was used to solubilize the alkaloid mixture. The culture plates were maintained under the same conditions described previously, and the same procedure was performed to evaluate the interaction of these substances.
For monotherapy with PZQ at the concentration of $0.5 \mu \mathrm{g} / \mathrm{mL}$, the percentage of dead adult worms was $33.0 \%$. At the concentration of $0.25 \mu \mathrm{g} / \mathrm{mL}$, there were no worms showing a total absence of movement. Upon exposure to $\mathrm{C} / \mathrm{E}$, the percentage of nonviability among parasites at the concentration of $23.8 \mu \mathrm{g} / \mathrm{mL}$ was $16 \%$. There were viable parasites at the concentration of $11.9 \mu \mathrm{g} /$ $\mathrm{mL}$. In comparison to monotherapy, the association of $\mathrm{PZQ}: \mathrm{C} / \mathrm{E}$ exhibited a stronger effect $(p<0.05)$ at the proportions of $0.5 / 23.8,0.5 / 11.9$ and $0.25 / 23.8 \mu \mathrm{g} / \mathrm{mL}$, with a shutdown effect on $83 \%, 50 \%$ and $80 \%$ of worms, respectively (Fig. 7 ). As observed for PZQ, the C/E mixture also caused excretory system paralysis and damage to the parasite tegument. This result suggests a possible synergistic effect, increasing the action on these targets or acting concomitantly on different targets to enhance the effect. $^{44,46-48}$ Interestingly, it was observed that while PZQ caused an effect of muscle contraction, C/E induced relaxation in worms, but these effects were not observed for the PZQ:C/E association.

The drug association effect is also a very important strategy to minimize therapeutical doses of an active composition, aiming at the reduction of possible toxic effects of substances, which could be used in smaller doses than when administered as single compounds. Thus, the association of drugs with synergistic effect has been widely studied and can be a valuable way to improve the 

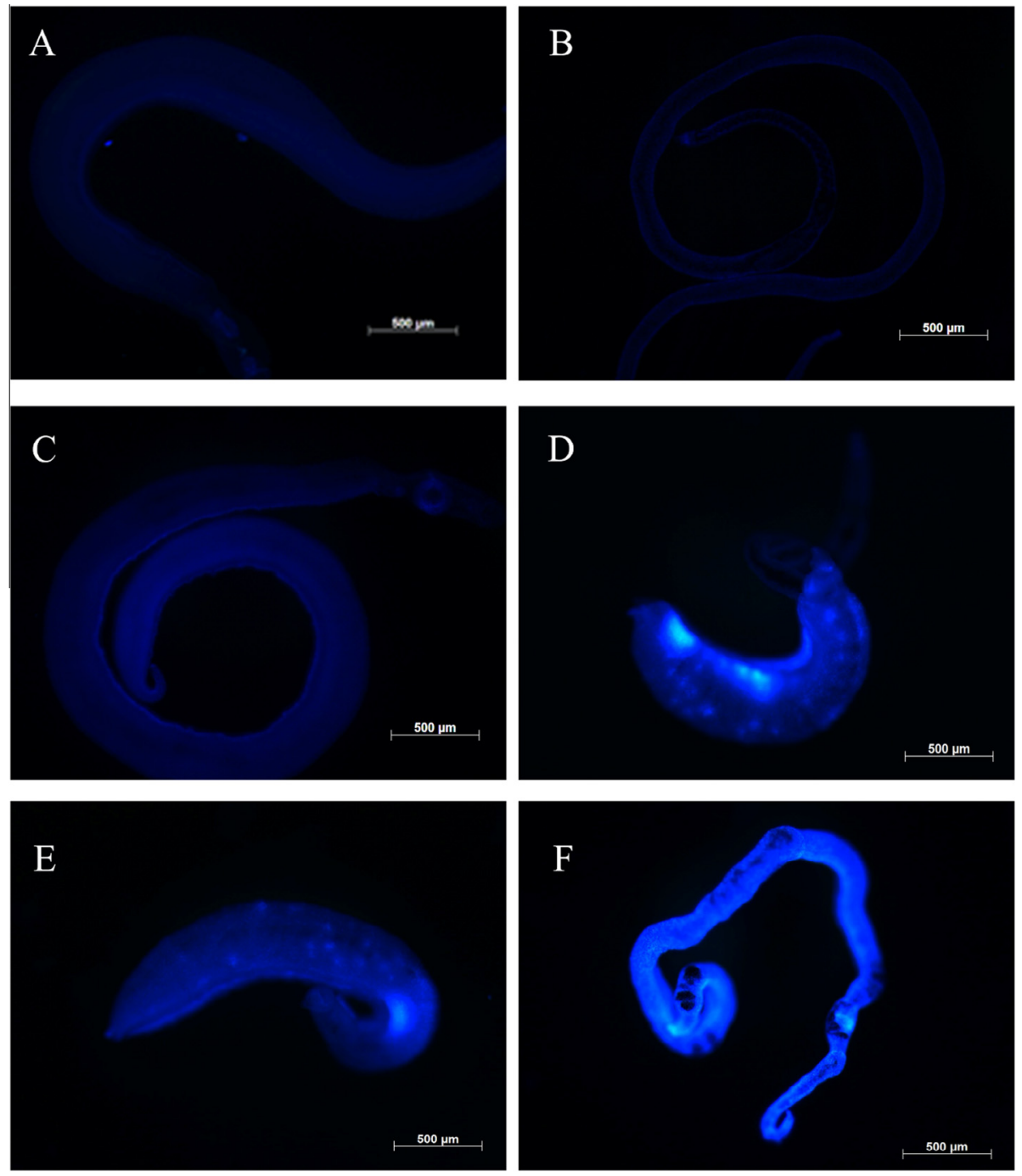

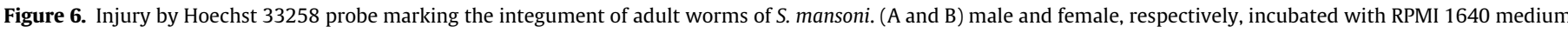

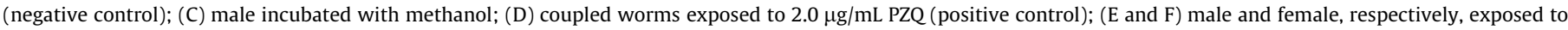
the $\mathrm{C} / \mathrm{E}$ mixture at $40 \mu \mathrm{g} / \mathrm{mL}$.

treatment of a number of diseases such as malaria, Chagas disease, giardiasis and schistosomiasis. ${ }^{44,45,47,48}$

The cercaricidal activity of the C/E was also evaluated by investigating the loss rates of motility and tail, by an adapted methodology described earlier. ${ }^{26}$ The loss of tail has been used as a measure of sensitivity to PZQ. ${ }^{49,50}$ However, the mechanism that causes this effect remains unclear. It is known that the cercariae body narrows in a close folding connection with the tail, and it is believed that this bond can be easily broken. ${ }^{49}$ Cercariaes are the infective form of the parasite for the definitive host, and for the penetration through the skin to occur, they need the combined action of enzyme secretion and tail vibrating movements. ${ }^{51}$ Consequently, the tail loss compromises the ability of cercaricidal infectivity. The tail loss induction by drug action is different from loss by physical stress, since the first occurs before the acetabular content is secreted, which was confirmed after exposure to PZQ. At concentrations of 12.5 and $25.0 \mu \mathrm{g} / \mathrm{mL}, \mathrm{C} / \mathrm{E}$ showed a weak effect. However, the effects were significantly higher from a concentration of $50.0 \mu \mathrm{g} / \mathrm{mL}(p<0.05)$, with $100 \%$ of loss in motility after $4 \mathrm{~h}$ and $75 \%$ of tail loss after the analysis time (Fig. 8). It might also be noted the formation of blisters and vacuolization in all concentrations. The effect of $\mathrm{C} / \mathrm{E}$ in the three highest concentrations was compatible or more efficient than the effect of PZQ. Thus, the action of the alkaloidal mixture C/E on larval stage is also proven, based on the same measure of sensitivity used for PZQ as well as by other studies carried out with Hinokitiol, Euphorbia conspicua and Garcinia braziliensis. ${ }^{26,51,52}$

Parasites are eukaryotes as well as their hosts, and besides, they share most of the biochemical and molecular characteristics. This is an obstacle for researchers working in the field of medicinal chemistry to obtain new, effective and selective drug candidate prototypes. Attention should be paid to the limitation to find prototypes simultaneously effective against the parasite but not toxic to humans when in vitro tests are performed. ${ }^{13}$ So, a cell viability assay was performed using the same methodology as described by Dias and co-workers. ${ }^{53}$ Our results suggest that the natural $\mathrm{C}$ / E mixture could be a promising alternative against $S$. mansoni, since it has exhibited significant potency against adult worms $\left(\mathrm{ED}_{50}=37.4 \mu \mathrm{g} / \mathrm{mL}\right)$ and moderate cytotoxic potential against human monocytes with a $\mathrm{CC}_{50}=132.1 \mu \mathrm{g} / \mathrm{mL}$ and a safety index of $\mathrm{SI}=3.5$. This activity profile is significantly interesting, as the toxic concentration for human monocytes is 3.5 times higher than the effective dose to kill the parasites. In fact, many studies concerning the cytotoxicity of alkaloids of different types reveal that 


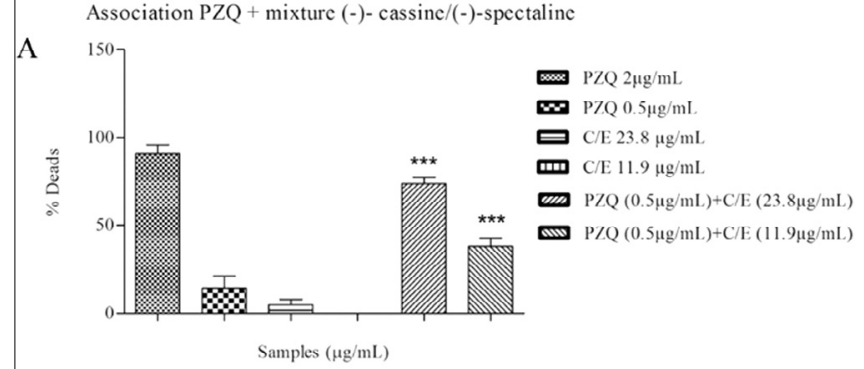

Association PZQ + mixture (-)-cassine/(-)-spectaline

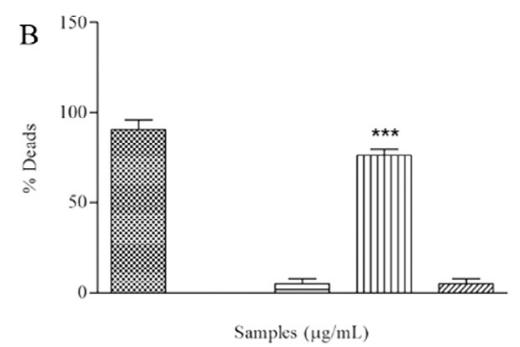

Figure 7. Schistosomicidal activity of the association of $\mathrm{PZQ}: \mathrm{C} / \mathrm{E}$ in comparison to monotherapy with PZQ $(0.5 \mu \mathrm{g} / \mathrm{mL})(A)$ and PZQ $(0.25 \mu \mathrm{g} / \mathrm{mL})(B)$ and with C/E.

they do not show high safety indices. An example of this toxic profile can be seen in the work of Mengome and co-workers ${ }^{54}$ in which monkey kidney cells were used for the cytotoxicity evaluation. In this same context, another recent study showed that 3alkylpyridine marine alkaloid analogues showed significant toxicity against murine peritoneal macrophages. ${ }^{55}$ Regarding to PZQ security index, it was conducted tests until the concentration of

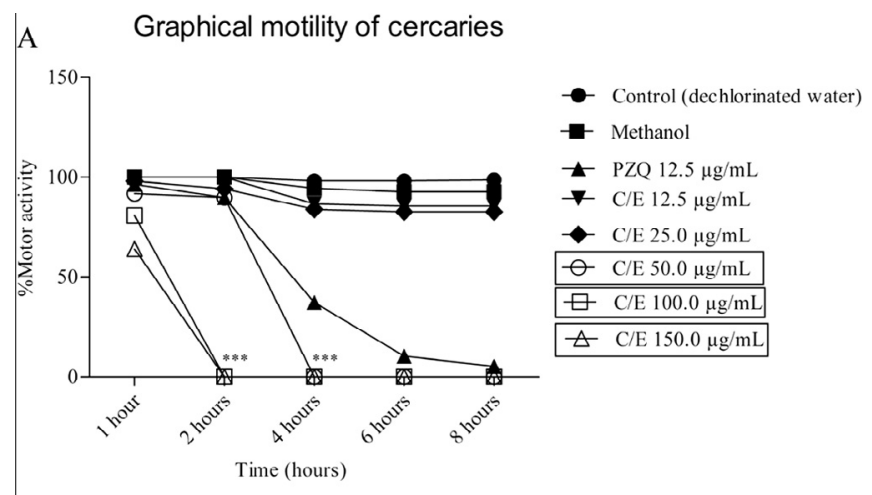

$\mathrm{B}$

Tail loss graph of cercaries

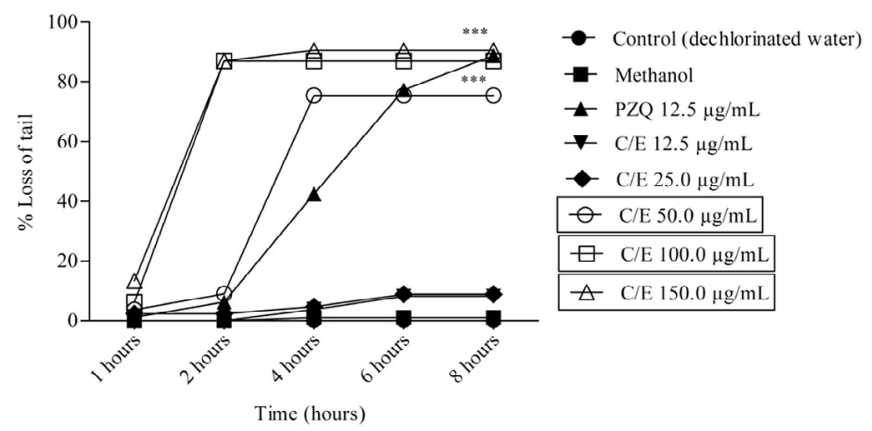

Figure 8. Effect at different concentrations of the $\mathrm{C} / \mathrm{E}$ mixture on the viability of cercariae, based on the rate (\%) of movement (A) and loss of tail (B). Data are presented as the average of three experiments. ${ }^{* * *} p<0.0001$.
$500.0 \mu \mathrm{g} / \mathrm{mL}$, but no toxicity was observed at murine macrophages (data not shown).

In conclusion, these data point to a promising schistosomicidal activity profile for this mixture of abundant natural alkaloids, (-)cassine and (-)-spectaline. Moreover, C/E seems to act by a multitarget mechanism, which could be related to inhibitory effects on excretory activity, tegument lesions, and possible action on neuromotor activity, as well as an effective toxic effect on the larval stage of cercariae. In addition, our results showed increased schistosomicidal activity when PZQ was used in combination with C/E. It suggests that C/E mixture or isolated (-)-cassine and (-)-spectaline compounds or other their semisynthetic derivatives could reinforce the therapeutic potency, specially against PZQ-resistant strains. Further studies of efficacy and toxicity are needed, as well as a deepened evaluation of the possible mechanisms involved. These findings could be of great value in the development of an innovative feature of these compounds for efficacy with a lower possibility of resistance or in the rational design of new drug candidates for schistosomiasis using (-)-cassine and (-)-spectaline as structural inspiration, considering that these two compounds are natural homologues with a great grade of structural similarity, differing only by two methylene groups on the lateral side chain. Finally, we have an ongoing project that aims to evaluate a series of C/E semi-synthetic derivatives for their schistossomicidal profile with higher potency and lower toxicity, which results will be published soon.

\section{Acknowledgments}

The authors are very grateful to FAPEMIG, CNPq and CAPES for financial support and fellowships and to Dr. Paulo Marcos Zech Coelho for his help and support.

\section{References and notes}

1. Oliveira, R. N.; Rehder, V. L. G.; Santos Oliveira, A. S.; Júnior, Í. M.; de Carvalho, J. E.; de Ruiz, A. L. T. G., et al. Exp. Parasitol. 2012, 132, 135.

2. Silva, G. B.; Duarte, D. B.; Barros, E. J. G.; De Francesco Daher, E. Asian Pacific J. Trop. Dis. 2013, 3, 79.

3. WHO, Schistosomiasis, WHO, World Health Organization, 2014.

4. Rapado, L. N.; Nakano, E.; Ohlweiler, F. P.; Kato, M. J.; Yamaguchi, L. F.; Pereira, C. A. B., et al. J. Helminthol. 2011, 85, 66.

5. Hotez, P. J.; Molyneux, D. H.; Fenwick, A.; Kumaresan, J.; Sachs, S. E.; Sachs, J. D., et al. N. Engl. J. Med. 2007, 357, 1018.

6. Mantawy, M. M.; Ali, H. F.; Rizk, M. Z. Rev. Inst. Med. Trop. Sao Paulo 2011, 53, 155.

7. Abdel-Hafeez, E. H.; Ahmad, A. K.; Abdulla, A. M.; Aabdel-Wahab, S.; Mosalem, F. A. Parasitol. Res. 2012, 111, 577.

8. De Moraes, J.; Nascimento, C.; Lopes, P. O. M. V.; Nakano, E.; Yamaguchi, L. F.; Kato, M. J., et al. Exp. Parasitol. 2011, 127, 357.

9. Oliveira, R. N.; Rehder, V. L. G.; Oliveira, A. S. S.; Jeraldo, V. D. L. S.; Linhares, A. X.; Allegretti, S. M. Exp. Parasitol. 2014, 139, 63.

10. Fabri, R. L.; Maria, D.; Aragão, D. O.; Florêncio, J. R.; De Castro, N.; Pinto, C., et al. Biomed. Res. Int. 2014, 1.

11. Godinho, L. S.; Soares, L.; De Carvalho, A.; Campos, C.; De Castro, B.; Dias, M. M., et al. Sci. World J. 2014, 1.

12. Carrara, V. S.; Vieira, S. C. H.; de Paula, R. G.; Rodrigues, V.; Magalhães, L. G.; Cortez, D. a. G., et al. J. Helminthol. 2013, 5, 1.

13. Wink, M. Molecules 2012, 17, 12771.

14. Silva, F.; Silva, M.; Cerqueira, G.; Sabino, E.; Almeida, A.; Costa, J., et al. J. Young Pharm. 2011, 3, 232.

15. Albuquerque Melo, G. M.; Silva, M. C. R.; Guimarães, T. P.; Pinheiro, K. M.; Da Matta, C. B. B.; De Queiroz, A. C., et al. Phytomedicine 2014, 21, 277.

16. Krishnan, N.; Ramanathan, S.; Sasidharan, S.; Murugaiyah, V.; Mansor, S. M. Int. J. Pharmacol. 2010, 6, 510.

17. Silva, F. O.; Silva, M. G. V.; Cerqueira, G. S.; Sabino, E. B.; Almeida, a. a. C.; Costa, J. P., et al. J. Young Pharm. 2011, 3, 1232.

18. Alexandre-Moreira, M. S.; Viegas, C.; Palhares De Miranda, A. L.; Bolzani, V. D. S.; Barreiro, E. J. Planta Med. 2003, 69, 795.

19. Viegas, C.; Silva, D. H. S.; Pivatto, M.; de Rezende, A.; Castro-Gambôa, I.; Bolzani, V. S., et al. J. Nat. Prod. 2007, 70, 2026.

20. Silva, D. H. S.; Viegas, C., Jr.; Santos, L.; Castro-Gamboa, I.; Cavalheiro, J.; Bolzani, V., et al. Rev. Virtual Química 2010, 2, 38.

21. Jothy, S. L.; Torey, A.; Darah, I.; Choong, Y. S.; Saravanan, D.; Chen, Y., et al. Molecules 2012, 17, 10292. 
22. Silva, K. a. B. S.; Manjavachi, M. N.; Paszcuk, A. F.; Pivatto, M.; Viegas, C.; Bolzani, V. S., et al. Neuropharmacology 2012, 62, 967.

23. Oliveira Silva, F.; De Vasconcelos Silva, M. G.; Feng, D.; De Freitas, R. M. Fitoterapia 2011, 82, 255.

24. Pivatto, M.; Crotti, A. E. M.; Lopes, N. P.; Castro-Gamboa, I.; De Rezende, A. Viegas, C., et al. J. Braz. Chem. Soc. 2005, 16, 1431.

25. Smithers, S. R.; Terry, R. J. Parasitology 1965, 55, 695.

26. Castro, A.; de Mattos, A.; Pereira, N.; Anchieta, N.; Silva, M.; Dias, D., et al. Planta Med. 2015, 81, 733.

27. Cioli, D.; Botros, S. S.; Wheatcroft-Francklow, K.; Mbaye, A.; Southgate, V.; Tchuenté, L.-A. T., et al. Int. J. Parasitol. 2004, 34, 979.

28. Magalhães, L. G.; Machado, C. B.; Morais, E. R.; Moreira, E. B. D. C.; Soares, C. S.; da Silva, S. H., et al. Parasitol. Res. 2009, 104, 1197.

29. Xiao, S.-H.; Keiser, J.; Chollet, J.; Utzinger, J.; Dong, Y.; Endriss, Y., et al. Antimicrob. Agents Chemother. 2007, 51, 1440.

30. El-Beshbishi, S. N.; Taman, A.; El-Malky, M.; Azab, M. S.; El-Hawary, A. K.; ElTantawy, D. Int. J. Parasitol. 2013, 43, 521.

31. Magalhães, L. G.; Kapadia, G. J.; da Silva Tonuc, i. L. R.; Caixeta, S. C.; Parreira, N. Rodrigues, V, et al Parasitol. Res, 2010, 106, 395.

32. Chai, Jong-Yil Infect Chemother. 2013, 45, 32

33. Cupit, P. M.; Cunningham, C. Future Med. Chem. 2015, 7, 701.

34. Ercoli, N. Exp. Parasitol. 1985, 216, 204.

35. Arnon, R.; Silman, I.; Tarrab-Hazdai, R. Protein Sci. 1999, 8, 2553.

36. Pessôa, R. F.; Castro, N. G.; Noël, F. Biochem. Pharmacol. 2005, 69, 1509.

37. Mellin, T. N.; Busch, R. D.; Wang, C. C.; Kath, G. Am. J. Trop. Med. Hyg. 1983, 32, 83.

38. Viegas, C.; Bolzani, V. S.; Pimentel, L. S. B.; Castro, N. G.; Cabral, R. F.; Costa, R. S., et al. Bioorg. Med. Chem. 2005, 13, 4184.

39. Sato, H.; Kusel, J. R.; Thornhill, J. Parasitology 2002, 125, 527.

40. Schinkel, H.; Jonker, J. W. Adv. Drug Delivery Rev. 2003, 55, 3.
41. Sotillo, J.; Pearson, M.; Becker, L.; Mulvenna, J.; Loukas, A. Int. J. Parasitol. Aust. Soc. Parasitol. 2015, 45, 505.

42. Pearce, E. J.; MacDonald, A. S. Nat. Rev. Immunol. 2002, 2, 499.

43. Couto, F. F. B.; Coelho, P. M. Z.; Araújo, N.; Kusel, J. R.; Katz, N.; Mattos, A. C. Parasitology 2010, 137, 1791.

44. Araujo, N.: De Mattos, A. C. A. Coelho, P. M. Z; Katz, N. Mem Inst Oswaldo Cruz. 2008, 103, 781

45. Mattos, A. C. A.; Pereira, G. C.; Jannotti-Passos, L. K.; Kusel, J. R.; Coelho, P. M. Z Acta Trop. 2007, 102, 84

46. Araújo, M. S.; Martins-Filho, O. A.; Pereira, M. E.; Brener, Z. J. Antimicrob Chemother. 2000, 45, 819.

47. Kuehn, C. C.; Rodrigues Oliveira, L. G.; Santos, C. D.; Ferreira, D. S.; Alonso Toldo, M. P.; De Albuquerque, S., et al. J. Pineal. Res. 2009, 47, 253.

48. Hausen, M. A.; Menna-Barreto, R. F. S.; Lira, D. C.; de Carvalho, L.; Barbosa, H. S. Parasitol. Int. 2011, 60, 54

49. Liang, Y. S.; Wang, W.; Dai, J. R.; Li, H. J.; Tao, Y. H.; Zhang, J. F., et al. J. Helminthol. 2010, 84, 202.

50. Santos, A. F.; Fonseca, S. A.; César, F. A.; De Azevedo Albuquerque, M. C. P.; Santana, J. V.: Santana, A. E. G. Parasitol. Res. 2014, 113, 1077.

51. Chisty, M. M.; Nargis, M.; Inaba, T.; Ishita, K.; Osanai, A.; Kamiya, H. Tohoku J. Exp. Med. 2004, 202, 63.

52. Aldenir, F.; De Azevedo, D. P. L.; Santos, C.; Dinis, D. I. M.; Mendonça, D.; Goulart, A. E., et al. Bioresour. Technol. 2007, 98, 135.

53. Dias, K. S. T.; Januário, J. P.; D’Dego, J. L.; Dias, A. L. T.; Dos Santos, M. H.; Camps, I., et al. Bioorg. Med. Chem. 2012, 20, 2713.

54. Mengome, L. E.; Akue, J. P.; Souza, A.; Feuya Tchoua, G. R.; Nsi Emvo, E. Parasitol. Res. 2010, 107, 643.

55. Machado, P. A.; Hilário, F. F.; Carvalho, L. O.; Silveira, M. L. T., et al. Chem. Biol. Drug Des. 2012, 80, 745. 